\author{
Izabela KASPRZYK ${ }^{1}$ \\ Magdalena SOSNOWSKA ${ }^{2}$ \\ Magdalena LACHOWICZ ${ }^{3}$ \\ Adam PODHORECKI ${ }^{4}$
}

\title{
NIEPRAWIDLOWO ZAPROJEKTOWANA \\ I WYKONANA INSTALACJA CIEPŁEJ WODY UŻYTKOWEJ W WIELORODZINNYM BUDYNKU MIESZKALNYM POWODEM WIELU PROBLEMÓW
}

\begin{abstract}
$\mathrm{W}$ artykule przedstawiono przykład nieprawidłowo zaprojekowanej i wykonanej instalacji ciepłej wody użytkowej w budynku mieszkalnym wielorodzinnym. W analizowanej instalacji c. w. u. często dochodziło do powstawania nieszczelności na skutek pękania zastosowanych kształtek. W celu określenia przyczyn nawracających destrukcji wykonano badania laboratoryjne wizualnej oceny kształtek w wyniku ogrzewania oraz pomiaru rozszerzalności termicznej. Badanie wizualnej oceny zmian w wyniku ogrzewania przeprowadzono wg normy PN-EN ISO 580: ,Systemy przewodów rurowych i rur osłonowych $z$ tworzyw sztucznych. Ksztattki wtryskowe z tworzyw termoplastycznych. Metody wizualnej oceny zmian w wyniku ogrzewania", natomiast drugie badanie, dotyczące rozszerzalności termicznej, przeprowadzono według indywidualnego projektu. Ponadto przeprowadzono wizję lokalną przedmiotowej instalacji, która ujawniła liczne błędy i nieprawidłowości wykonawcze.
\end{abstract}

Słowa kluczowe: instalacja ciepłej wody użytkowej, błędy projektowe, błędy wykonawcze, elementy instalacji nieznanego pochodzenia

\section{Wprowadzenie}

Instalacja ciepłej wody użytkowej powinna być zaprojektowana i wykonana w taki sposób, aby zapewniona była odpowiednia trwałość systemu oraz, co naj-

\footnotetext{
${ }^{1}$ Autor do korespondencji/corresponding author: Izabela Kasprzyk, Uniwersytet Technologiczno Przyrodniczy im. Jana i Jędrzeja Śniadeckich w Bydgoszczy, Al. Prof. S. Kaliskiego 7, 85-796 Bydgoszcz, izabelakasprzykutp@gmail.com

2 Magdalena Sosnowska, Uniwersytet Technologiczno - Przyrodniczy im. Jana i Jędrzeja Śniadeckich w Bydgoszczy, Al. Prof. S. Kaliskiego 7, 85-796 Bydgoszcz, sosnowska.m@o2.pl

${ }^{3}$ Magdalena Lachowicz, Uniwersytet Technologiczno - Przyrodniczy im. Jana i Jędrzeja Śniadeckich w Bydgoszczy, Al. Prof. S. Kaliskiego 7, 85-796 Bydgoszcz, magdalena.lachowicz@utp.edu.pl

${ }^{4}$ Adam Podhorecki, Uniwersytet Technologiczno - Przyrodniczy im. Jana i Jędrzeja Śniadeckich w Bydgoszczy, Al. Prof. S. Kaliskiego 7, 85-796 Bydgoszcz, podhorec@utp.edu.pl
} 
ważniejsze bezpieczeństwo użytkowania. $\mathrm{Z}$ uwagi na kontakt rur $\mathrm{z}$ wodą pitną, użyte materiały i wyroby muszą bezwzględnie posiadać certyfikat CE (dopuszczający je do obrotu) oraz atest Państwowego Zakładu Higieny. Do wykonania instalacji wodnej najczęściej stosuje się rury miedziane lub z tworzyw sztucznych, takich jak: polietylen (PE), polipropylen (PP), czy polichlorek winylu (PCW). Ważne jest to, aby nie stosować w jednej instalacji elementów z różnych materiałów. Błędem jest także łączenie rur i kształtek różnych producentów.

$\mathrm{W}$ artykule zostanie omówiony przykład nieprawidłowo wykonanej instalacji ciepłej wody użytkowej (c. w. u.) w budynku wielorodzinnym. Analizowana instalacja c. w. u. została wykonana $\mathrm{z}$ tworzywa sztucznego. Zastosowane w niej kształtki zaczęły ulegać uszkodzeniu, co wielokrotnie powodowało nieszczelność instalacji. Po wymianie spękanych elementów, uszkodzenia odnawiały się po pewnym czasie. Autorzy artykułu wykonali ekspertyzę, której celem było ustalenie przyczyn powstających uszkodzeń kształtek stosowanych w instalacjach wewnętrznych ciepłej wody użytkowej.

\section{Badania laboratoryjne kształtek (próbek)}

W analizowanym przypadku wielokrotnie dochodziło do rozszczelnienia instalacji ciepłej wody na skutek pękania kształtek. Aby sprawdzić jakość kształtek oraz ocenić ich pracę w przypadku znacznych zmian temperatury, poddano kilka próbek (stanowiących fragment wykonanej instalacji) następującym badaniom:

- wizualnej ocenie zmian w wyniku ogrzania,

- pomiarom rozszerzalności termicznej.

Do badań przeznaczono 5 kształtek ponumerowanych od 1-5 (fot. 1), które służyły do łączenia rur o średnicy zewnętrznej $32 \mathrm{~mm}$ w badanym budynku. Próbki

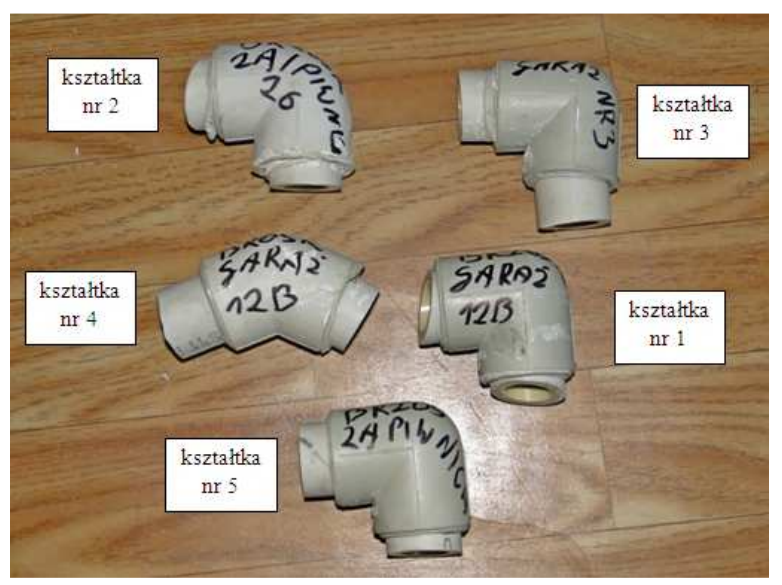

Fot. 1. Badane kształtki, próbki

Phot. 1. Tested fittings 
wykonane były z polipropylenu (PP). Polipropylen jest jednym z najczęściej stosowanych tworzyw sztucznych. Powstaje on w wyniku niskociśnieniowej polimeryzacji propylenu. Do kształtek dołączone były fragmenty rur polipropylenowych (połączenie zgrzewane). Brakowało dokładnych danych źródłowych odnoszących się do typów poszczególnych kształtek. Na podstawie opisów zawartych na kształtkach ustalono, że mają one następujące symbole i oznaczenia:

- kolanko nr 1 - typ PP-R PN 2.5 WB L32, producent nieznany,

- kolanko nr 2 - typ ustalony, producent ustalony,

- kolanko nr 3 - typ PP-R PN 2.5 WBL32, producent nieznany,

- kolanko nr 4 - typ nieznany, producent ustalony,

- kolanko nr 5 - typ PP-R PN 2.5 WBL 32, producent nieznany.

Pierwsze badanie to ocena wizualna kształtek w wyniku ogrzania. Badanie przeprowadzono wg normy PN-EN ISO 580: „Systemy przewodów rurowych i rur ostonowych z tworzyw sztucznych. Ksztattki wtryskowe z tworzyw termoplastycznych. Metody wizualnej oceny zmian w wyniku ogrzewania" [1]. Celem badania było ustalenie tego, w jaki sposób wzrost temperatury wpływa na stan techniczny kształtek. Kształtki poddano działaniu podwyższonej temperatury $\left(150^{\circ} \mathrm{C}\right)$, w suszarce $\mathrm{z}$ obiegiem powietrza w określonym czasie (30 minut), zależnym od grubości ścianki i materiału, z którego wykonana jest kształtka (polipropylen, gr. ścianki $3 \div 10 \mathrm{~mm}$ ). Powierzchnie kształtek sprawdzane były przed ogrzewaniem i po ogrzewaniu. Dokładnie obserwowano powstałe destrukcje, tj. pęknięcia, pęcherze, rozwarstwienia. Wyniki badań przedstawiono w tab. 1 . Na fot. $2 \div 6$ widoczny jest stan próbek po badaniu.
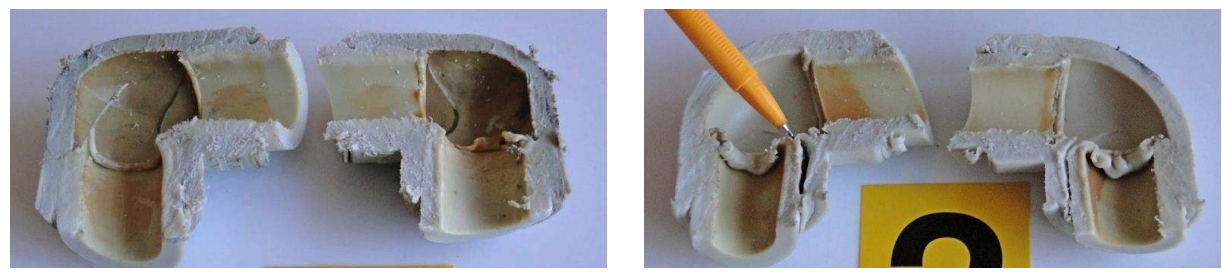

Fot. 2, 3. Kształtka nr 1 (po lewej) i nr 2 (po prawej) po badaniu (opis w tabeli 1)

Phot. 2, 3. Fitting No. 1 (left) and No. 2 (right) after the test (described in Table 1)
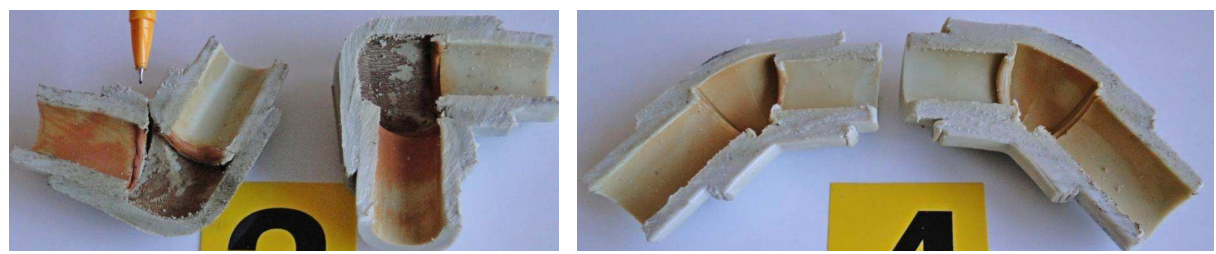

Fot. 4, 5. Kształtka nr 3 (po lewej) i nr 4 (po prawej) po badaniu (opis w tabeli 1)

Phot . 4, 5. Fitting No. 3 (left) and No. 4 (right) after the test (described in Table 1) 


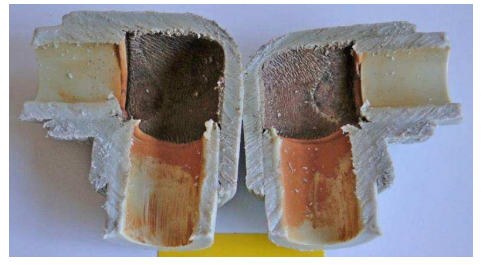

Fot. 6. Kształtka nr 5 po badaniu (opis w tabeli 1)

Phot . 6. Fitting No. 5 after the test (described in Table 1)

Tabela 1. Wyniki badań wizualnej oceny zmian kształtek w wyniku ogrzewania

Table 1 . The test results of visual evaluation of changes fittings by heating

\begin{tabular}{|c|c|c|}
\hline $\begin{array}{c}\text { Oznaczenie } \\
\text { kształtki } \\
\text { (próbki) }\end{array}$ & $\begin{array}{c}\text { Grubość } \\
\text { ścianki } \\
\text { [mm] }\end{array}$ & Wynik badania \\
\hline $\begin{array}{c}\text { Nr 1 } \\
\text { PP-R PN } 2.5 \\
\text { WB L32 }\end{array}$ & $\begin{array}{c}5,34 ; 5,80 \\
6,08 \\
\text { Srednia: } \\
5,74\end{array}$ & $\begin{array}{l}\text { Pozytywny: Nie zauważono pęknięć, rozwar- } \\
\text { stwień, pęcherzy. Końcówki rur wpuszczone do } \\
\text { kolanka uległy niewielkiemu uplastycznieniu. Rury } \\
\text { są koloru jasnego, a kolanko - koloru szarego, co } \\
\text { świadczy o tym, że elementy te nie pochodzą z tego } \\
\text { samego systemu (fot. 2). }\end{array}$ \\
\hline $\begin{array}{l}\text { Nr } 2 \\
\text { Ustalony pro- } \\
\text { ducent }\end{array}$ & $\begin{array}{c}6,93 ; 6,90 \\
7,16 \\
\text { Średnia: } \\
7,00\end{array}$ & $\begin{array}{l}\text { Negatywny: Nastąpiło rozwarstwienie w miejscu } \\
\text { połączenia (zgrzania) rury i kształtki. Końcówki rur } \\
\text { i kolanka uległy mocnemu uplastycznieniu. Kolor } \\
\text { rur i kolanka jednorodny - jasny. Widoczne jest } \\
\text { niewielkie zabrudzenie osadem (fot. } 3 \text { ). }\end{array}$ \\
\hline $\begin{array}{c}\text { Nr 3 } \\
\text { PP-R PN 2.5 } \\
\text { WB L32 }\end{array}$ & $\begin{array}{c}6,09 ; 5,30 \\
5,79 \\
\text { Srednia: } \\
5,73\end{array}$ & $\begin{array}{l}\text { Negatywny: Kolanko uległo pęknięciu. Ponadto } \\
\text { zauważa się mocne zabrudzenie (przebarwienie). } \\
\text { Końcówki rur są lekko uplastycznione. Rury są } \\
\text { koloru jasnego a kolanko koloru szarego, co świad- } \\
\text { czy o tym, że elementy te nie pochodzą z tego sa- } \\
\text { mego systemu (fot. 4). }\end{array}$ \\
\hline $\begin{array}{l}\mathrm{Nr} \mathbf{4} \\
\text { Ustalony pro- } \\
\text { ducent }\end{array}$ & $\begin{array}{c}\text { 7,37; 7,30; } \\
\text { 6,55 } \\
\text { Srednia: } \\
\text { 7,07 }\end{array}$ & $\begin{array}{l}\text { Pozytywny: Nie zauważono pęknięć, rozwar- } \\
\text { stwień, pęcherzy, nastąpiło tylko lekkie uplastycz- } \\
\text { nienie końcówki jednej rury. Kolor rur i kolanka } \\
\text { jest jednorodny - jasny. Widoczne jest niewielkie } \\
\text { zabrudzenie (fot. 5). }\end{array}$ \\
\hline $\begin{array}{c}\text { Nr } 5 \\
\text { PP-R PN } 2.5 \\
\text { WB L32 }\end{array}$ & $\begin{array}{c}5,79 ; 3,88 \\
6,28 \\
\text { Srednia: } \\
5,32\end{array}$ & $\begin{array}{l}\text { Pozytywny: Nie zauważono pęknięć, rozwar- } \\
\text { stwień, pęcherzy. Końcówki rur są lekko uplastycz- } \\
\text { nione. Bardzo mocne zabrudzenia (przebarwienia). } \\
\text { Widoczne lekkie oddzielenie rur od kolanka. Rury } \\
\text { są koloru jasnego a kolanko koloru szarego, co } \\
\text { świadczy o tym, że elementy te nie pochodzą z tego } \\
\text { samego systemu (fot. 6). }\end{array}$ \\
\hline
\end{tabular}


Drugie badanie, dotyczące rozszerzalności termicznej, przeprowadzono według indywidualnego projektu. Celem badania było ustalenie przyrostu wydłużenia kształtek w zależności od wzrastającej temperatury w przedziale $30 \div 110{ }^{\circ} \mathrm{C}$. Badanie polegało na obserwacji i pomiarze zmian liniowych $\mathrm{w}$ wybranych temperaturach $\mathrm{z}$ analizowanego przedziału w odstępach czasowych 1 godziny. Na badanych kształtkach zaznaczono bazę pomiarową o długości $24 \mathrm{~mm}$, która posłużyła do pomiaru zmian liniowych. Przyjmuje się, że dla polipropylenu (PP) współczynnik rozszerzalności termicznej liniowej wynosi $\alpha_{\mathrm{t}}=0,150 \frac{\mathrm{mm}}{\mathrm{m}^{\circ} \mathrm{C}}$. Przewody PP ulegają zatem stosunkowo dużym odkształceniom termicznym. Na podstawie wyników pomiaru przyrostu długości bazy pomiarowej (wynoszącej $24 \mathrm{~mm}$ ) i przyporządkowanej temperatury sporządzono dwa następujące wykresy:

- wykres względnego przyrostu długości $\Delta$ l odniesionej do długości bazowej w funkcji temperatury $\varepsilon(T)$ (rys. 1),

- wykres umownego współczynnika rozszerzalności termicznej w funkcji temperatury at(T) (rys. 2).

Kształtki, w zakresie temperatur do $100^{\circ} \mathrm{C}$, zachowywały się prawidłowo, tj. nie zauważono istotnych deformacji, pęknięć lub miejsc z obniżoną wytrzymałością termiczną. Od temperatury $100^{\circ} \mathrm{C}$ kształtki zaczynały się uplastyczniać. Stwierdzono najmniejszą rozszerzalność termiczną w kształtce $\mathrm{nr} 4$. Kształtki typu PP-R PN 2.5 WBL 32 i typu $\Sigma$ Li były znacznie bardziej wrażliwe na wydłużenie termiczne. Wartości funkcji rozszerzalności termicznej zależą od temperatury i mieszczą się w następującym przedziale (rys. 2):

- kształtka nr $1-0,41 \div 1,63 \frac{\mathrm{mm}}{\mathrm{m}^{\circ} \mathrm{C}}$,

- kształtka nr $2-0,37 \div 0,75 \frac{\mathrm{mm}}{\mathrm{m}^{\circ} \mathrm{C}}$,

- kształtka nr $3-0,37 \div 1,17 \frac{\mathrm{mm}}{\mathrm{m}^{\circ} \mathrm{C}}$,

- kształtka $\mathrm{nr} 4-0,24 \div 0,46 \frac{\mathrm{mm}^{\circ}}{\mathrm{m}^{\circ} \mathrm{C}}$,

- kształtka nr $5-0,27 \div 0,96 \frac{\mathrm{mm}^{\circ}}{\mathrm{m}^{\circ} \mathrm{C}}$.

Najlepsze, najkorzystniejsze rezultaty otrzymano dla kształtki $\mathrm{nr} 4$, a najgorsze dla kształtki nr 1 . Zmiana długości, np. rury, kształtki jest proporcjonalna do współczynnika rozszerzalności termicznej $\alpha_{\mathrm{t}}$, tzn. im współczynnik rozszerzalności termicznej jest większy, tym przyrost długości także jest większy, a to przekłada się w praktyce na rozmieszczenie podpór i kompensatorów.

Zwraca się uwagę na dużą zmienność współczynnika $\alpha_{\mathrm{t}} \mathrm{w}$ zależności od temperatury (rys. 1 i 2). Wyjątkiem jest tutaj kształtka nr 4, której rozszerzalność termiczna jest dość stabilna. 


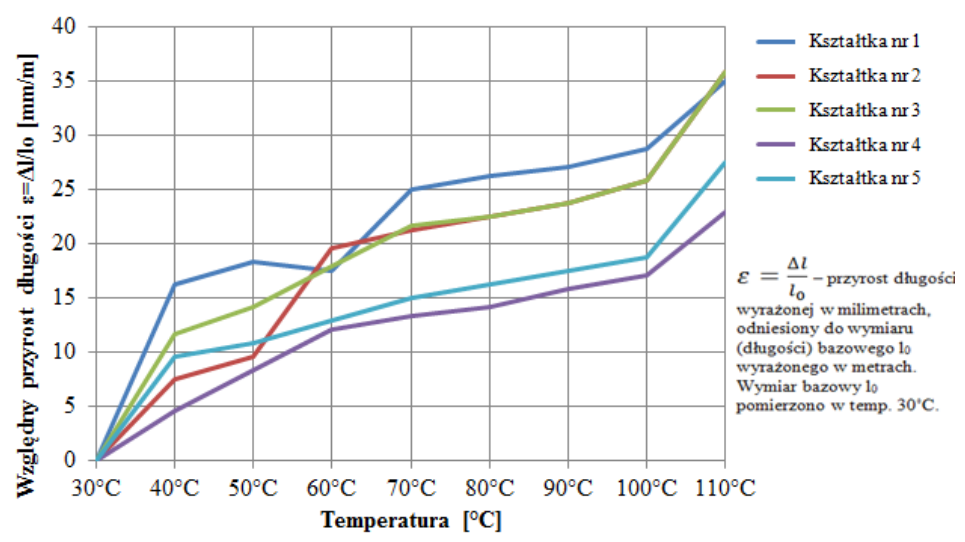

Rys. 1. Wykres względnego przyrostu długości w zależności od temperatury

Fig. 1. A graph of relative growth in length depending on the temperature

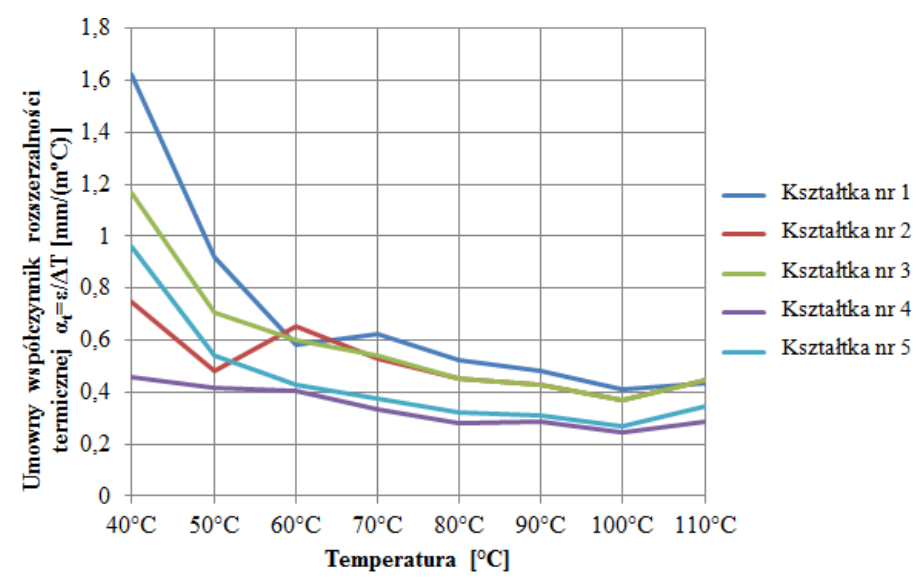

Rys.2.Wykres umownego współczynnika rozszerzalności termicznej w zależności od temperatury

Fig. 2. A graph of coefficient of thermal expansion depending on the temperature

\section{Badania dotyczące jakości robót budowlanych}

Pod wpływem temperatury, rury ciepłej wody ulegają wydłużeniu lub skróceniu o wartość:

$$
\Delta l=l \cdot \Delta T \cdot \alpha_{t},
$$

gdzie: $\Delta l$-wielkość wydłużenia (skrócenia) [mm],

$l$ - długość przewodu (np. odległość od podpory do kompensatora) [m], $\Delta T$ - różnica pomiędzy temp. montażu a temp. pracy instalacji [K], $\alpha_{t}$ - współczynnik rozszerzalności termicznej $[\mathrm{mm} /(\mathrm{mK})]$. 
Siły sprężystości powstające w rurach (w wyniku rozszerzalności tych rur) działające na punkty stałe (podpory nieprzesuwne) określa się ze wzoru:

$$
F=E A \cdot \Delta T \cdot \alpha_{t},
$$

gdzie: $F$ - siła sprężystości [N],

$E$ - moduł sprężystości rury $\left[\mathrm{N} / \mathrm{m}^{2}\right]$,

$A$ - pole przekroju poprzecznego rury $\left[\mathrm{m}^{2}\right]$.

$\mathrm{W}$ przypadku, gdy wydłużenia nie mogą być skompensowane przez naturalne załamanie rurociągu należy stosować kompensatory. Do tego celu - w przypadku rur PP - stosuje się kompensatory w kształcie litery „U” lub/i pętlicowe (rys. 3). W środku kompensatora zaleca się montować punkt stały (podporę stałą). Na podstawie wizji lokalnej na przedmiotowym budynku stwierdzono liczne nieprawidłowości w wykonaniu instalacji ciepłej wody, wynikające ze zbyt gęstego rozmieszczenia podpór stałych. Powoduje to, że na wielu odcinkach nie jest możliwa kompensacja wydłużenia spowodowanego zmianą temperatury (fot. 7). W ocenianej instalacji zastosowano tylko cztery kompensatory (fot. 8) a w kilku miejscach kompensacja następuje poprzez naturalne załamanie instalacji w planie (samokompensacja) (rys. 4). Ponadto w żadnym z kompensatorów nie przestrzegano zalecenia, dotyczącego montażu podpory stałej w środku kompensatora (rys. 3).

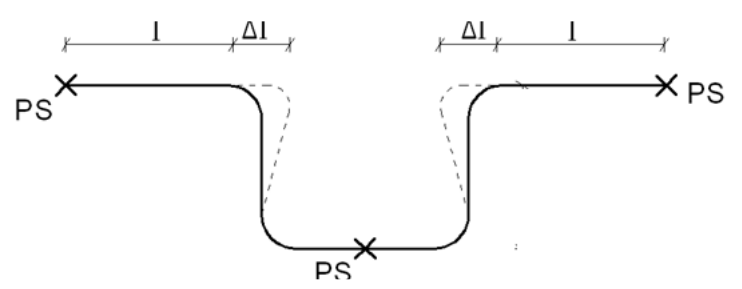

Rys. 3. Kompensator typu U (PS - podpora stała; $\Delta l$ - wydłużenie lub skrócenie długości przewodu spowodowane zmianą temperatury, $l$ - długość przewodu)

Fig. 3. U - shape compensator

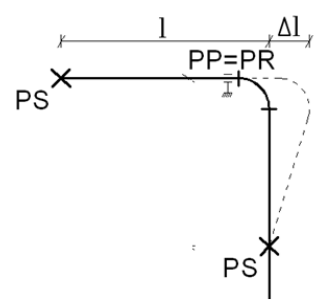

Rys. 4. Przykłady samokompensacji (kompensacji naturalnej) przewodów wykonanych z polipropylenu (PS - podpora stała; $\mathrm{PP}=\mathrm{PR}$ - podpora przesuwna, ruchoma; $\Delta l$ - wydłużenie lub skrócenie długości przewodu spowodowane zmianą temperatury, $l$ - długość przewodu)

Fig. 4. Examples of natural compensation pipes made of polypropylene 


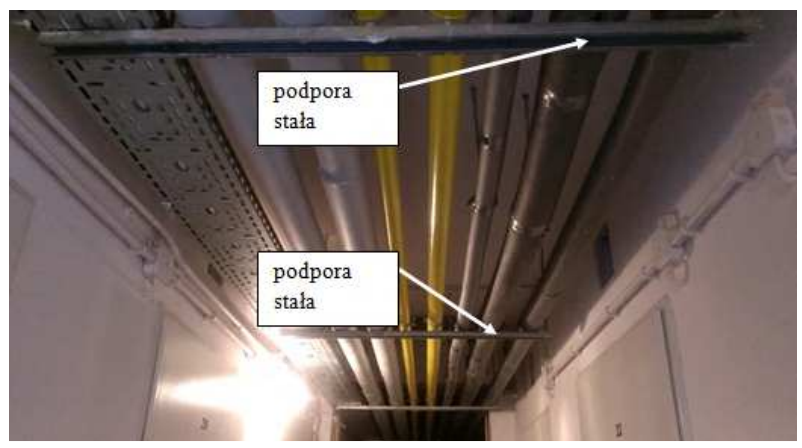

Fot. 7. Nieprawidłowy fragment instalacji ciepłej wody; pomiędzy dwiema podporami stałymi nie jest możliwa kompensacja wydłużenia spowodowanego zmianą temperatury (brakuje kompensatora)

Phot . 7. Incorrect part of the installation of hot water; between the two permanent supports is not possible to extend the compensation due to temperature change (missing compensator)

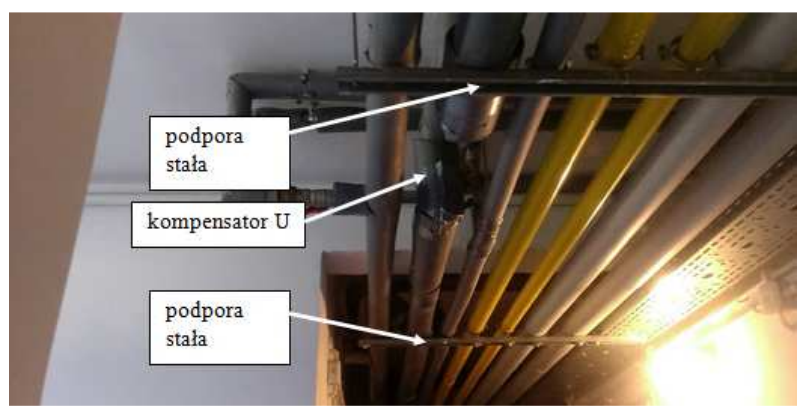

Fot. 8. Prawidłowy fragment instalacji ciepłej wody; pomiędzy dwiema podporami stałymi zastosowano kompensator typu $\mathrm{U}$

Phot . 8. The correct part of the installation of hot water; between the two permanent supports used U-shape compensator

\section{Analiza wyników badań i wnioski}

1. Głównym celem badań przedstawionych w niniejszym artykule była ocena kształtek (kolanek), użytych do wykonania instalacji ciepłej wody w budynku wielorodzinnym. Należało określić, czy ewentualna wadliwość kształtek mogła być przyczyną częstych awarii instalacji ciepłej wody. Awarie te zawsze wynikały z nieszczelności i uszkodzeń kształtek.

2. W projektach wykonawczych analizowanego budynku mieszkalnego określono, że instalację c. w. u. należy wykonać z rur plastikowych PP typu BOR (jest to kompletny system instalacyjny produkowany $\mathrm{z}$ polipropylenu PP-R typu 3; w skład systemu wchodzą: rury PP klas PN10, PN16, PN20, rury PP stabilizowane perforowaną wkładką aluminiową, kształtki PP, zawory kulo- 
we i grzybkowe; łączenie rur i kształtek odbywa się poprzez zgrzewanie polifuzyjne). Na dołączonych do projektu rysunkach zaznaczono trasy instalacji, ale brakowało jakiegokolwiek opisu i rysunków rozmieszczenia podpór stałych, ruchomych (przesuwnych), kompensatorów itp.

3. W analizowanym budynku mieszkalnym brakowało udokumentowania faktycznie wbudowanych rur i kształtek. Do wykonania instalacji ciepłej wody użyto kształtek i rur co najmniej trzech różnych producentów, co jest w istocie błędem. Brakowało atestów higienicznych i deklaracji zgodności kształtek poszczególnych producentów.

4. W ramach przeprowadzonych badań laboratoryjnych kształtek stwierdzono, co następuje:

- badaniu poddano 5 kształtek, 3. różnych producentów, przy czym dwóch różnych producentów zostało ustalonych (kształtka nr 2 i kształtka nr 4),

- wyniki poszczególnych badań laboratoryjnych można uznać za pozytywne tylko tych kształtek, w których ustalono producenta, w pozostałych przypadkach wyniki są negatywne.

5. Oceniono stan techniczny instalacji ciepłej wody faktycznie wykonanej $\mathrm{w}$ analizowanym obiekcie budowlanym. Wyniki tej oceny są negatywne z następujących podstawowych powodów:

- brak logicznego rozmieszczenia podpór stałych, przesuwnych (nieliczne) i kompensatorów, co powoduje przypadkową kompensację rur od zmieniającej się temperatury,

- ocieplenie instalacji c. w. u. wykonano niestarannie.

6. Stwierdzono ostatecznie następujące przyczyny awarii sieci (instalacji) ciepłej wody w analizowanym budynku:

- projekt ma liczne braki a wykonawstwo instalacji c. w. u. jest nieprawidłowe, dotyczy to rozmieszczenia podpór stałych, przesuwnych i kompensatorów,

- wbudowano w sieć kształtki (kolanka) nieznanego pochodzenia, o nieustabilizowanej, nadmiernej rozszerzalności termicznej, małej odporności na podwyższoną temperaturę; pozytywnym wyjątkiem są jedynie kolanka, dla których znany jest producent.

7. Odpowiedzialność za powstały awaryjny stan instalacji ciepłej wody $\mathrm{w}$ analizowanych budynkach ponoszą:

- wykonawca (kierownik budowy) i inspektor nadzoru inwestorskiego, za złe, nieprawidłowe wykonawstwo,

- projektant, za braki w dokumentacji projektowej.

\section{Podsumowanie}

Instalacja ciepłej wody użytkowej, tak jak i inne instalacje, powinna być zaprojektowana i wykonana z należytą starannością, bowiem ta woda jest używana np. do picia, mycia itp. W związku z tym zupełnie naturalne są stawiane 
specjalne wymagania nie tylko dotyczące jakości wody, ale także jakości instalacji itp. Oczywistym staje się więc postulat, że użyte materiały i wyroby muszą bezwzględnie spełniać określone wymogi higieniczne (o szerokim zakresie). Oznacza to wprost, że instalację ciepłej wody muszą tworzyć materiały i wyroby spełniające dokładnie i jednoznacznie obowiązujące wymogi formalne, czego w rozważanym przypadku brakuje. Jest to absolutnie niedopuszczalne. Nieprawidłowo wykonana instalacja c. w. u. może wpływać znacząco na jakość wody. Niesie to zagrożenie dla zdrowia osób korzystających z takiej instalacji. Ponadto konieczność częstych napraw instalacji w analizowanym budynku jest bardzo uciążliwa dla mieszkańców.

\title{
Literatura
}

[1] PN-EN ISO 580: „Systemy przewodów rurowych i rur osłonowych z tworzyw sztucznych. Kształtki wtryskowe z tworzyw termoplastycznych. Metody wizualnej oceny zmian w wyniku ogrzewania".

\section{WRONG DESIGNED AND INSTALLED SANITARY HOT WATER SYSTEM IN MULTI-FAMILY RESIDENTIAL BUILDING REASON OF MANY PROBLEMS}

\begin{abstract}
S u m m a r y
The article contains an example of incorrectly designed and made hot water installation in multi-family residential building. In the analyzed water system frequently some leaks happened due to cracking of the applied profiles. In order to determine the causes of recurrent destruction of laboratory tests were carried out visually assessed molded by heating and the measurement of thermal expansion. The study of visual assessment of changes as a result of the heating was carried out according to the PN-EN ISO 580: "Piping systems and casing pipes with plastic. Injectionmolded parts made of thermoplastic materials. Methods of visual assessment of changes due to the heating", and the second test on thermal expansion was carried out by individual project. In addition, a site inspection of the installation was conducted, which revealed numerous errors and irregularities regulations.
\end{abstract}

Keywords: installation of hot water, design errors, implementing errors, system components of unknown origin

Przestano do redakcji: 07.06.2016 $r$.

Przyjęto do druku: 30.06 .2016 r.

DOI: $10.7862 / \mathrm{rb} .2016 .1$ 